\title{
Maternal dietary glycaemic load during pregnancy and gestational weight gain, birth weight and postpartum weight retention: a study within the Danish National Birth Cohort
}

\author{
Vibeke K. Knudsen ${ }^{1,2 *}$, Berit L. Heitmann ${ }^{3}$, Thorhallur I. Halldorsson ${ }^{1,4}$, Thorkild I. A. Sørensen ${ }^{3}$ \\ and Sjurdur F. Olsen ${ }^{1,5}$ \\ ${ }^{1}$ Department of Epidemiology Research, Statens Serum Institut, Centre for Fetal Programming, DK-Copenhagen S, Denmark \\ ${ }^{2}$ Division of Nutrition, National Food Institute, Technical University of Denmark, Mørkhøj Bygade 19, DK-2860, \\ Søborg, Denmark \\ ${ }^{3}$ Institute of Preventive Medicine, Copenhagen University Hospital, Copenhagen, Denmark \\ ${ }^{4}$ Unit for Nutrition Research, Faculty of Food Science and Nutrition, School of Health Sciences, University of Iceland, \\ Reykjavik, Iceland \\ ${ }^{5}$ Harvard School of Public Health, Centre for Fetal Programming, Boston, MA, USA \\ (Submitted 17 October 2011 - Final revision received 6 July 2012 - Accepted 6 July 2012 - First published online 21 August 2012)
}

\begin{abstract}
Dietary glycaemic index and glycaemic load (GL) have been related to obesity and other health outcomes. The objective of the present study was to examine the associations between maternal dietary GL and gestational weight gain, birth weight, the risk of giving birth to a child large-for-gestational age (LGA) or small-for-gestational age and postpartum weight retention (PPWR). Data were derived from the Danish National Birth Cohort (1996-2002), including data on gestational and lifestyle factors in pregnancy and 18 months postpartum. Dietary data were collected using a validated FFQ. Information on birth outcome was obtained through registers. A total of 47003 women were included. The associations between the GL and birth outcome, gestational weight gain, assessed between weeks 12 and 30 of gestation, and PPWR were analysed by linear and logistic regression. Birth weight increased by $36 \mathrm{~g}$ from the lowest to highest GL quintile $(95 \%$ CI 19, $53 \mathrm{~g}$ ), and an increased risk of LGA of $14 \%$ was detected in the highest GL quintile compared with the lowest GL quintile. Among normal-weight and overweight women, higher gestational weight gain rates were detected in the highest GL quintile (26 g/week (95\% CI 19, 34) and $30 \mathrm{~g} /$ week $(95 \%$ CI 13, 46), respectively). The association between the GL and PPWR was most pronounced among pre-pregnant obese women, with an increase in weight retention of $1.3(95 \%$ CI $0 \cdot 2,2 \cdot 8) \mathrm{kg}$ from the lowest to highest GL quintile. The GL may play a role for excessive gestational weight gain and PPWR, which may be more pronounced among overweight and obese women.
\end{abstract}

Key words: Maternal dietary glycaemic load: Birth weight: Postpartum weight retention

A part of a successful pregnancy is an optimal weight gain of the mother to ensure a sufficient supply of nutrients to the fetus and the mother. However, excessive weight gain during pregnancy may increase the risk of complications in relation to pregnancy and delivery ${ }^{(1)}$, and has been reported to be an independent risk factor for caesarean section ${ }^{(2,3)}$, the risk of pre-eclampsia ${ }^{(4,5)}$ and gestational diabetes ${ }^{(6,7)}$. Further, excessive gestational weight gain may increase the risk of postpartum weight retention (PPWR) ${ }^{(8,9)}$, which may induce obesity in later life ${ }^{(10-13)}$. In addition, high gestational weight gain has been reported to increase the risk of infants born large-for-gestational age (LGA) ${ }^{(14)}$ in a large birth cohort.

The dietary glycaemic index (GI) was introduced in 1981 by Jenkins et al. ${ }^{(15)}$ as a classification of carbohydrate-rich foods according to the rise in blood glucose after ingestion. Examples of foods with a high GI are potatoes, white bread and rice, while dairy products, legumes and nuts are foods with a low GI. It was originally developed as a tool for diabetic patients to improve the administration of their postprandial glycaemic responses. GI is the glycaemic response after ingesting $50 \mathrm{~g}$ of available carbohydrate as a percentage

Abbreviations: DNBC, Danish National Birth Cohort; GI, glycaemic index; GL, glycaemic load; LGA, large-for-gestational age; PPWR, postpartum weight retention; SGA, small-for-gestational age.

*Corresponding author: V. K. Knudsen, email vkkn@food.dtu.dk 
of the response after eating the corresponding amount of carbohydrate from a reference food (white bread or glucose). Pregnancy has been reported not to alter the GI of foods ${ }^{(16)}$. The glycaemic load (GL) of the diet is the product of the amount of available carbohydrate for each food item and the GI of the food, summed for all foods consumed ${ }^{(15,17-19)}$. The GL includes both the quality and the quantity of carbohydrate in the diet, and thus is an indicator for the total glucose response ${ }^{(20)}$, and it has been suggested that the GL of the diet may be an important measure in epidemiological studies, as the carbohydrate contents of the diet may vary substantially ${ }^{(21)}$.

A diet with a high GI has been associated with an increased risk of obesity ${ }^{(17,22)}$, as some observational studies have reported positive associations between the GI and $\mathrm{BMI}^{(23-26)}$, while others have found no association ${ }^{(27,28)}$. In a review of randomised controlled trials, it was concluded that diets with a low GI were more promoting in weight loss compared with control diets ${ }^{(29)}$, and a diet with a low GI has additionally been reported to improve weight maintenance after a previous weight loss in a randomised controlled trial $^{(30)}$. The GI has also been related to reproductive outcome: higher birth weight and a higher prevalence of babies born LGA have been detected in infants born of women assigned to high-GI diets compared with women with isoenergetic low-GI diets in randomised controlled trials ${ }^{(31,32)}$, while a low-GL diet prevented prematurity and improved lipid profiles in pregnant women in another randomised trial ${ }^{(33)}$. In an observational study, a higher risk of having a baby small-forgestational age (SGA) defined as infants with a birth weight below the 10th percentile for a given gestational age was found among mothers following a low-GI diet ${ }^{(34)}$. The findings reflect the fact that glucose is a major substrate for fetal growth $^{(35)}$, and thus may be associated with fetal overgrowth. Further, a positive association between dietary GI and maternal weight gain was found in a small randomised controlled trial ${ }^{(31)}$; however, the results were not confirmed in an observational study by Deierlein et al. ${ }^{(36)}$.

The hypotheses to be tested in the present study are that pregnant women consuming a diet with a high GL may have an increased risk of excessive maternal weight gain and PPWR, and that a high dietary GL may be a risk factor for giving birth to a child LGA, or that a low dietary GL is associated with an increased risk of giving birth to a child SGA. Furthermore, it is hypothesised that the associations will be more pronounced among pre-pregnancy overweight women due to impaired glucose control.

\section{Subjects and methods}

The Danish National Birth Cohort (DNBC) is a nationwide survey, including 101042 women recruited in weeks 6-10 of gestation. Data were collected from 1996 to 2002 by means of an enrolment form, and four telephone interviews in weeks 12 and 30 of gestation, and 6 and 18 months postpartum, recording information on gestational, anthropometric and lifestyle factors ${ }^{(37)}$. All women participating in the DNBC gave written informed consent in accordance with the
Helsinki II Declaration, and the study was approved by the Danish National Committee for Biomedical Research Ethics, Copenhagen (protocol no. KF-01-471/94 and KF-01-012/97).

\section{Study population}

Of the total participants, 70188 women returned the FFQ. Of these, $1934(2 \cdot 8 \%)$ were excluded due to unrealistic reporting of energy intake $(<4.2 \mathrm{MJ}$ and $>16.7 \mathrm{MJ})$. Of the remaining 68254 women, data on gestational weight gain and other lifestyle factors obtained from telephone interviews were available for 41782 women, and, among them, data on maternal weight 18 months postpartum were available for 24586 women.

Maternal diet was assessed by means of a self-administered FFQ in week 25 of gestation. Assessment of dietary and nutrient intake was done by means of a national food composition database (http://www.foodcomp.dk) using standard recipes and standard portion sizes. The 360-item FFQ covered the intake of food and drinks during the previous 4 weeks ${ }^{(38)}$. It has been validated using a $7 \mathrm{~d}$ weighed food record and biomarkers as a standard, and the results showed that the FFQ was capable of ranking individuals according to the total energy intake and the intake of protein and retinol ${ }^{(39)}$.

Values of the GI for a variety of foods were extracted from published data ${ }^{(40)}$ using white bread as reference, and were incorporated into the dietary database. The overall GI of the diet was calculated by summing the products of the amounts of available carbohydrate for each food item and the GI of the particular food, divided by the total intake of available carbohydrate. The GL was calculated as the sum of the amounts of intakes of available carbohydrates multiplied by the GI of the foods and thus corresponds to the numerator of the GI. Dietary GI and GL were calculated by the following formulas ${ }^{(41)}$ :

$$
\begin{aligned}
\mathrm{GI} & =\Sigma\left(\mathrm{GI}_{i} \times \mathrm{CHO}_{i}\right) / \Sigma \mathrm{CHO}_{i}, \\
\mathrm{GL} & =\Sigma\left(\mathrm{GI}_{i} \times \mathrm{CHO}_{i}\right) / 100
\end{aligned}
$$

where $\mathrm{GI}_{i}$ is the GI value of food $i$ and $\mathrm{CHO}_{i}$ represents the amount of available carbohydrate from food $i$. All nutrients and GL were adjusted for total energy using the residual $\operatorname{method}^{(42)}$.

\section{Outcome}

The gestational weight gain rate of women was assessed as mean weight gain in $\mathrm{g} /$ week from week 12 (first interview) to week 30 (second interview) of gestation. As some dispersion in gestation week of the two interviews occurred, cases with less than $60 \mathrm{~d}$ in between the two data collections were recorded as missing with regard to weight gain to obtain a reasonable time period to register the weight change accurately. PPWR was calculated by subtracting the pre-pregnancy body weight from the postpartum weight reported 18 months after delivery. Information on birth outcome, including birth weight and gestational age, was derived from the National Patient Registry. We calculated $z$-scores for 
birth weight for all births in the DNBC using the growth reference from the British Child Growth Foundation ${ }^{(43)}$, taking into account gestational age at delivery and the infant's sex. The distribution was used to estimate the proportion of infants born LGA as infants born with birth weight above the 90th percentile for a given gestational age, and infants born SGA as infants born with birth weight below the 10th percentile for a given gestational age.

\section{Covariates}

The following covariates were included in the analyses: total energy intake (MJ) to adjust for potential residual confounding, as suggested by Willett et al. ${ }^{(42)}$, parity, maternal pre-pregnant BMI, smoking habits in pregnancy (never, former, occasional, $<15$ cigarettes/d or $\geq 15$ cigarettes/d), physical activity during pregnancy (yes $v$. no), mother's age ( $<20$ years, $20-40$ years or $>40$ years) and height $(>160 \mathrm{~cm}$, $160-169 \mathrm{~cm}, 170-179 \mathrm{~cm}$ or $\geq 180 \mathrm{~cm}$ ), and couple's sociodemographic group, defined by the job description of the woman and her partner.

\section{Statistical analyses}

Women were divided into quintiles according to dietary GL. Differences in gestational weight gain rate, birth weight and PPWR in the groups of GL were analysed by linear regression. Differences in ratios of LGA and SGA babies in quintiles of GL were analysed by means of logistic regression analyses. The trend test was performed by the $\chi^{2}$ test (type III) with GL as

Table 1. Dietary intake and maternal characteristics by quintile of glycaemic load

(Mean values and standard deviations; percentages) a continuous variable in the regression model. All analyses were performed as univariate analyses, and with adjustment for the above-mentioned confounding factors. In analyses of birth weight, adjustments of gestational weight gain rate were performed, and in analyses of PPWR, data on gestational weight gain rate and breast-feeding duration were included, as the latter has been observed to be associated with PPWR ${ }^{(44)}$. In addition, women were stratified according to pre-pregnant BMI (underweight, BMI $<18.5 \mathrm{~kg} / \mathrm{m}^{2}$; normal weight, BMI $18.5-24.9 \mathrm{~kg} / \mathrm{m}^{2}$; overweight, $\mathrm{BMI} \geq 25-29.9 \mathrm{~kg} / \mathrm{m}^{2}$; obese, BMI $\geq 30 \mathrm{~kg} / \mathrm{m}^{2}$ ), and all aforementioned analyses were performed within each stratum of BMI. All analyses were performed using SAS version 9.1 (SAS Institute, Inc.).

\section{Results}

The dietary intakes in quintiles of GL are shown in Table 1. A slight decrease in total energy intake was seen with increasing GL, although the absolute difference between the highest and lowest groups was small (Spearman's correlation coefficient $-0.01, P=0.002)$. Dietary fibre intake and intake of carbohydrate increased with increasing GI (Spearman's correlation coefficient $0 \cdot 24(P<0 \cdot 001)$ and $0 \cdot 34(P<0 \cdot 001)$, respectively), while intakes of fat and protein decreased (Spearman's correlation coefficient $-0.38(P<0.001)$ and $-0.18(P<0.001)$, respectively). Age and pre-pregnancy BMI were the same in all groups, although a slight tendency towards increasing age was detected. The proportion of never smokers increased with increasing GL, as did the proportion of women being physically active during leisure time. Small differences were seen in

\begin{tabular}{|c|c|c|c|c|c|c|c|c|c|c|c|}
\hline \multirow[t]{2}{*}{ Glycaemic load... } & \multicolumn{2}{|c|}{ Q1 (n 13639) } & \multicolumn{2}{|c|}{ Q2 (n 13644) } & \multicolumn{2}{|c|}{ Q3 (n 13639) } & \multicolumn{2}{|c|}{ Q4 (n 13643) } & \multicolumn{2}{|c|}{ Q5 (n 13636) } & \multirow[b]{2}{*}{$P$ for trend } \\
\hline & Mean & SD & Mean & SD & Mean & SD & Mean & $\mathrm{SD}$ & Mean & SD & \\
\hline Total energy intake (MJ) & $10 \cdot 0$ & $2 \cdot 6$ & $10 \cdot 0$ & $2 \cdot 4$ & $9 \cdot 9$ & $2 \cdot 3$ & 9.9 & $2 \cdot 3$ & 9.9 & $2 \cdot 4$ & $0.0004^{*}$ \\
\hline Fat $(g / d) \dagger$ & 96 & 14 & 85 & 11 & 79 & 11 & 73 & 10 & 64 & 11 & $<0.0001^{\star}$ \\
\hline Carbohydrate $(g / d) \dagger$ & 273 & 14 & 302 & 16 & 319 & 16 & 335 & 17 & 360 & 17 & $<0.0001^{\star}$ \\
\hline Dietary fibre $(\mathrm{g} / \mathrm{d}) \dagger$ & 23 & 6 & 26 & 6 & 27 & 6 & 28 & 7 & 28 & 7 & $<0.0001^{\star}$ \\
\hline Protein $(g / d) \dagger$ & 94 & 14 & 92 & 13 & 90 & 12 & 88 & 11 & 81 & 12 & $<0.0001^{\star}$ \\
\hline Glycaemic index $†$ & 78 & 21 & 79 & 20 & 80 & 20 & 81 & 20 & 83 & 21 & $<0.0001^{\star}$ \\
\hline Age (years) & 30 & 4 & 30 & 4 & 30 & 4 & 29 & 4 & 29 & 4 & $<0.0001^{\star}$ \\
\hline BMl $\left(\mathrm{kg} / \mathrm{m}^{2}\right)$ & 24 & 4 & 24 & 4 & 24 & 4 & 24 & 4 & 24 & 4 & $0.4195^{\star}$ \\
\hline \multicolumn{12}{|l|}{ Smoking (\%) } \\
\hline Never & \multicolumn{2}{|c|}{67} & \multicolumn{2}{|c|}{76} & \multicolumn{2}{|c|}{78} & \multicolumn{2}{|c|}{79} & \multicolumn{2}{|c|}{79} & $<0.0001 \ddagger$ \\
\hline Occasionally & \multicolumn{2}{|c|}{14} & \multicolumn{2}{|c|}{13} & \multicolumn{2}{|c|}{12} & \multicolumn{2}{|c|}{12} & \multicolumn{2}{|c|}{13} & \\
\hline$<15$ cigarettes/d & \multicolumn{2}{|c|}{16} & \multicolumn{2}{|c|}{10} & \multicolumn{2}{|c|}{9} & \multicolumn{2}{|c|}{8} & \multicolumn{2}{|c|}{7} & \\
\hline$\geq 15$ cigarettes $/ d$ & \multicolumn{2}{|c|}{4} & \multicolumn{2}{|c|}{2} & \multicolumn{2}{|c|}{1} & \multicolumn{2}{|c|}{1} & \multicolumn{2}{|c|}{1} & \\
\hline \multicolumn{12}{|c|}{ Leisure-time physical activity (\%) } \\
\hline Yes & \multicolumn{2}{|c|}{32} & \multicolumn{2}{|c|}{35} & & & & & & & $<0.0001 \ddagger$ \\
\hline No & & & & & & & & & & & \\
\hline Sociodemographic group & & & & & & & & & & & \\
\hline High & & & & & & & & & & & $<0.0001 \ddagger$ \\
\hline Intermediary & & & & & & & & & & & \\
\hline Skilled workers & & & & & & & & & & & \\
\hline Unskilled workers & & & & & & & & & & & \\
\hline Students & & & & & & & & & & & \\
\hline Not working & & & & & & & & & & & \\
\hline
\end{tabular}

*Test for trend ( $\chi^{2}$ test, type III).

†Adjusted for total energy intake by the residual method.

$\ddagger \chi^{2}$ test. 
couples' sociodemographic group, pointing towards a higher sociodemographic class with increasing GL.

As the GL includes both the quantity and the quality of dietary carbohydrate and thus has been reported to be an appropriate measure in epidemiological studies, and as only weak associations were detected regarding the GI and the outcomes, the focus in the Results section is therefore on the GL and the outcome.

\section{Birth weight}

The crude and adjusted differences in birth weight within the groups divided by quintiles of GL are shown in Table 2. Overall, birth weight increased with increasing GL, the highest increase being $36 \mathrm{~g}$ in women above the fifth quintile of dietary GL. When stratifying according to pre-pregnancy
BMI, the effect of the GL diminished among the underweight and obese women, while it was still statistically significant among the normal-weight women (34 g/week) and even more pronounced among the overweight women $(57 \mathrm{~g} /$ week). The confounding factors with the highest impact on the association between birth weight and the GL were smoking in pregnancy, maternal BMI and weight gain rate.

\section{Large-for-gestational age}

The risk of being born LGA was higher in the group with the highest GL; the risk was increased by $14 \%$ (OR 1.14; $95 \% \mathrm{CI}$ $1.03,1.25$; Table 2). When stratifying according to prepregnancy BMI, the tendencies for an increased risk of LGA by increasing the GL remained in all four weight classes, although not statistically significant.

Table 2. Crude and adjusted differences in birth weight in quintiles of glycaemic load, and crude and adjusted odd ratios for babies born large-forgestational age (LGA) and small-for-gestational age (SGA)

(Mean values and $95 \%$ confidence intervals; OR and $95 \%$ confidence intervals)

\begin{tabular}{|c|c|c|c|c|c|c|c|c|c|c|c|c|}
\hline & \multicolumn{4}{|c|}{ Birth weight $(\mathrm{g})$} & \multicolumn{4}{|c|}{$\mathrm{LGA}^{*}$} & \multicolumn{4}{|c|}{$S G A^{*}$} \\
\hline & \multicolumn{2}{|c|}{ Crude } & \multicolumn{2}{|c|}{ Adjusted $\dagger$} & \multicolumn{2}{|r|}{ Crude } & \multicolumn{2}{|c|}{ Adjusted $\dagger$} & \multicolumn{2}{|r|}{ Crude } & \multicolumn{2}{|c|}{ Adjusted } \\
\hline & Mean & $95 \% \mathrm{Cl}$ & Mean & $95 \% \mathrm{Cl}$ & OR & $95 \% \mathrm{Cl}$ & OR & $95 \% \mathrm{Cl}$ & OR & $95 \% \mathrm{Cl}$ & OR & $95 \% \mathrm{Cl}$ \\
\hline \multicolumn{13}{|c|}{ All women $\neq(n 41782)$} \\
\hline Q1 & \multicolumn{2}{|c|}{ Reference } & \multicolumn{2}{|c|}{ Reference } & \multicolumn{2}{|c|}{ Reference } & \multicolumn{2}{|c|}{ Reference } & \multicolumn{2}{|c|}{ Reference } & \multicolumn{2}{|c|}{ Reference } \\
\hline Q2 & 40 & 26,54 & 22 & 5,38 & $1 \cdot 11$ & $1.02,1 \cdot 21$ & 1.08 & $0.99,1.18$ & 0.85 & $0.76,0.94$ & 0.95 & $0.85,1.07$ \\
\hline Q3 & 42 & 27,56 & 35 & 19,52 & 1.09 & $1.00,1.19$ & 1.07 & $0.98,1.17$ & 0.89 & $0.80,0.96$ & 1.00 & $0.89,1 \cdot 12$ \\
\hline Q4 & 35 & 21,50 & 29 & 12,46 & $1 \cdot 10$ & $1.00,1.19$ & $1 \cdot 12$ & $1.02,1.22$ & 0.91 & $0.82,1.00$ & 1.02 & $0.90,1.14$ \\
\hline Q5 & 37 & 22,51 & 36 & 19,53 & 1.03 & $0.95,1.12$ & $1 \cdot 14$ & $1.03,1.25$ & \multirow{2}{*}{\multicolumn{2}{|c|}{$\begin{array}{c}0.88 \\
0.110\end{array}$}} & 0.94 & $0.83,1.06$ \\
\hline$P$ & \multicolumn{2}{|c|}{$<0.001$} & \multicolumn{2}{|c|}{$<0.001$} & \multicolumn{2}{|c|}{0.480} & \multicolumn{2}{|c|}{0.007} & & & \multicolumn{2}{|c|}{0.640} \\
\hline \multicolumn{13}{|c|}{ Underweight ( $n$ 1705) } \\
\hline Q1 & \multicolumn{2}{|c|}{ Reference } & & erence & & eference & & eference & & eference & & eference \\
\hline Q2 & -30 & $-93,34$ & -26 & $-97,45$ & 0.77 & $0.40,1.46$ & 0.79 & $0.40,1.55$ & 1.44 & $0.96,2.14$ & 1.80 & $1 \cdot 66,2 \cdot 77$ \\
\hline Q3 & -58 & $-123,7$ & -62 & $-136,11$ & 0.89 & $0.47,1.67$ & 1.00 & $0.51,1.95$ & 1.25 & $0.82,1.88$ & 1.57 & $0.99,2.50$ \\
\hline Q4 & -30 & $-94,35$ & -19 & $-94,56$ & 0.94 & $0.51,1.75$ & $1 \cdot 11$ & $0.56,2 \cdot 20$ & 1.40 & $0.93,2.11$ & 1.81 & $1 \cdot 15,2 \cdot 85$ \\
\hline Q5 & -28 & $-92,37$ & 0 & $-78,77$ & 0.94 & $0.50,1.74$ & $1 \cdot 14$ & $0.57,2.30$ & 0.95 & $0.61,1.49$ & 1.23 & $0.74,2.06$ \\
\hline$P$ & & 354 & & 868 & & 0.977 & & 0.538 & & 0.959 & & 0.332 \\
\hline Norma & eight $(r$ & 8394) & & & & & & & & & & \\
\hline Q1 & & rence & & erence & & eference & & eference & & eference & & eference \\
\hline Q2 & 47 & 29,64 & 26 & 6,45 & $1 \cdot 15$ & $1.04,1.29$ & $1 \cdot 11$ & $0.99,1.24$ & 0.81 & $0.71,0.93$ & 0.90 & $0.78,1.03$ \\
\hline Q3 & 44 & 26,62 & 34 & 14,53 & $1 \cdot 10$ & $1.00,1.23$ & $1 \cdot 10$ & $0.97,1.23$ & 0.89 & $0.78,1.01$ & 0.97 & $0.85,1.12$ \\
\hline Q4 & 36 & 19,54 & 25 & 5,45 & 1.08 & $0.97,1.21$ & $1 \cdot 10$ & $0.98,1.23$ & 0.87 & $0.76,0.99$ & 0.95 & $0.83,1 \cdot 10$ \\
\hline Q5 & 35 & 18,53 & 34 & 14,54 & 1.02 & $0.91,1.13$ & $1 \cdot 10$ & $0.96,1.23$ & 0.87 & $0.77,0.99$ & 0.93 & $0.80,1.07$ \\
\hline$P$ & & 004 & & 004 & & 0.745 & & 0.265 & & 0.140 & & 0.628 \\
\hline Overn & ght $(n 82$ & & & & & & & & & & & \\
\hline Q1 & & rence & & erence & & eference & & eference & & eference & & eference \\
\hline Q2 & 29 & $-6,64$ & 5 & $-34,44$ & $1 \cdot 11$ & $0.94,1.32$ & 1.05 & $0.88,1.26$ & 0.85 & $0.66,1.10$ & 1.0 & $0.77,1.32$ \\
\hline Q3 & 51 & 16,87 & 52 & 13,92 & 1.05 & $0.88,1.25$ & 0.98 & $0.82,1.18$ & 0.79 & $0.61,1.02$ & 0.94 & $0.71,1.24$ \\
\hline Q4 & 34 & $-1,69$ & 39 & $-1,79$ & 1.06 & $0.90,1.26$ & 1.04 & $0.86,1.25$ & 0.93 & $0.72,1.18$ & $1 \cdot 10$ & $0.84,1.45$ \\
\hline Q5 & 67 & 32,102 & 57 & 15,98 & 1.12 & $0.94,1.33$ & 1.12 & $0.99,1.44$ & 0.82 & $0.64,1.06$ & 0.89 & $0.67,1.20$ \\
\hline$P$ & & 001 & & 002 & & 0.368 & & 0.125 & & 0.287 & & 0.708 \\
\hline Obese & 7429) & & & & & & & & & & & \\
\hline Q1 & & rence & & erence & & eference & & eference & & eference & & eference \\
\hline Q2 & 33 & $-24,90$ & 23 & $-38,84$ & 0.91 & $0.72,1.15$ & 0.90 & $0.70,1 \cdot 15$ & 0.83 & $0.57,1.21$ & 0.92 & $0.61,1.37$ \\
\hline Q3 & 37 & $-21,95$ & 29 & $-34,91$ & 1.03 & $0.81,1.29$ & 1.03 & $0.81,1.32$ & 0.93 & $0.64,1.34$ & 1.05 & $0.70,1.57$ \\
\hline Q4 & 38 & $-20,96$ & 25 & $-38,89$ & $1 \cdot 12$ & $0.89,1.41$ & 1.20 & $0.94,1.53$ & 0.98 & $0.68,1.42$ & 1.05 & $0.70,1.60$ \\
\hline Q5 & -20 & $-79,38$ & -44 & $-112,23$ & 0.87 & $0.68,1.11$ & 1.04 & $0.79,1.36$ & 1.07 & $0.75,1.54$ & 1.04 & $0.68,1.60$ \\
\hline$P$ & & 644 & & 352 & & 0.832 & & 0.205 & & 0.484 & & 0.698 \\
\hline
\end{tabular}

* Defined by means of growth reference values from the British Child Growth Foundation.

†Adjusted for total energy intake, fibre intake, parity, mother's age, pre-pregnancy BMI, gestational weight gain, smoking habits, physical activity and couple's sociodemographic group.

‡All women and stratified for pre-pregnancy BMI (underweight, BMI <18.5 kg/m²; normal weight, BMI $18.5-24.9 \mathrm{~kg} / \mathrm{m}^{2} ;$ overweight, BMI $25 \cdot 0-29.9 \mathrm{~kg} / \mathrm{m}^{2}$; obese, BMI $\left.\geq 30 \mathrm{~kg} / \mathrm{m}^{2}\right)$. 


\section{Small-for-gestational age}

In the unadjusted analyses, there was a small reduced risk of SGA with increasing GL, but when adjusting for potential confounders, the effect was no longer statistically significant. Among women with pre-pregnancy BMI below $18.5 \mathrm{~kg} / \mathrm{m}^{2}$, the risk of having a SGA baby was lowest in the group with the lowest dietary GL, which is opposite of the overall results. In the other BMI groups, no association between the GL and SGA was detected.

\section{Gestational weight gain rate}

Gestational weight gain rate was assessed as mean weight gain from week 12 to week 30 of gestation, including only data for women with at least $60 \mathrm{~d}$ in between the two measurements (median 113d, interquartile range 94-131d). The differences in gestational weight gain within the quintiles of $\mathrm{GL}$ are shown in Table 3. When looking at the whole group, higher gestational weight gain rates were observed in quintiles $2-5$ compared with women in the lowest quintile. However, when women were stratified according to pre-pregnancy BMI, no association was found among the underweight women, while the effect remained statistically significant among the normalweight and overweight women. The greatest difference in gestational weight gain rate was $30 \mathrm{~g} /$ week, corresponding to a difference in the total gestational weight gain of $1.2 \mathrm{~kg}$, among the overweight women in the adjusted analyses. Among the obese women, there was a tendency, although not statistically significant that gestational weight gain increased with GL.

Table 3. Crude and adjusted differences in gestational weight gain rate and 18 months postpartum weight retention (PPWR) in quintiles of glycaemic load

(Mean values and $95 \%$ confidence intervals)

\begin{tabular}{|c|c|c|c|c|c|c|c|c|}
\hline & \multicolumn{4}{|c|}{$\begin{array}{l}\text { Difference in gestational weight gain rate } \\
\qquad(\mathrm{g} / \text { week) }\end{array}$} & \multicolumn{4}{|c|}{ Difference in PPWR $(\mathrm{kg})$} \\
\hline & \multicolumn{2}{|c|}{ Crude } & \multicolumn{2}{|c|}{ Adjusted* } & \multicolumn{2}{|c|}{ Crude } & \multicolumn{2}{|c|}{ Adjusted $\dagger$} \\
\hline & Mean & $95 \% \mathrm{Cl}$ & Mean & $95 \% \mathrm{Cl}$ & Mean & $95 \% \mathrm{Cl}$ & Mean & $95 \% \mathrm{Cl}$ \\
\hline All women $\ddagger$ & \multicolumn{4}{|c|}{ n 43985} & \multicolumn{4}{|c|}{ n 24586} \\
\hline Q1 & \multicolumn{2}{|c|}{ Reference } & \multicolumn{2}{|c|}{ Reference } & \multicolumn{2}{|c|}{ Reference } & \multicolumn{2}{|c|}{ Reference } \\
\hline Q2 & 19 & 12,25 & 17 & 11,23 & 0.07 & $-0.08,0.23$ & 0.16 & $-0.04,0.35$ \\
\hline Q3 & 22 & 16,29 & 21 & 15,28 & 0.10 & $-0.05,0.26$ & 0.29 & $0.07,0.50$ \\
\hline Q4 & 29 & 23,35 & 27 & 20,33 & 0.17 & $0.02,0.33$ & 0.44 & $0.21,0.66$ \\
\hline Q5 & 30 & 24,36 & 28 & 21,34 & 0.22 & $0.07,0.38$ & 0.46 & $0.21,0.70$ \\
\hline$P$ & \multicolumn{2}{|c|}{$<0.001$} & \multicolumn{2}{|c|}{$<0.001$} & \multirow{2}{*}{\multicolumn{3}{|c|}{0.002}} & 0.001 \\
\hline Underweight & \multicolumn{4}{|c|}{$n 1797$} & & & & \\
\hline Q1 & & ence & & ence & \multicolumn{2}{|c|}{ Reference } & \multicolumn{2}{|c|}{ Reference } \\
\hline Q2 & 13 & $-12,38$ & 7 & $-19,33$ & -0.17 & $-0.57,0.23$ & 0.42 & $-0.10,0.93$ \\
\hline Q3 & 6 & $-19,32$ & 8 & $-19,35$ & -0.33 & $-0.74,0.08$ & 0.43 & $-0.15,1.01$ \\
\hline Q4 & 8 & $-18,33$ & 11 & $-16,39$ & -0.09 & $-0.50,0.32$ & 0.58 & $-0.04,1.20$ \\
\hline Q5 & -3 & $-29,23$ & -6 & $-34,22$ & -0.50 & $-0.91,-0.10$ & 0.31 & $-0.37,0.99$ \\
\hline$P$ & \multicolumn{2}{|c|}{0.832} & \multicolumn{2}{|c|}{0.939} & \multicolumn{2}{|r|}{0.040} & \multicolumn{2}{|r|}{0.372} \\
\hline Normal weight & \multicolumn{4}{|c|}{$n 29867$} & \multirow{2}{*}{\multicolumn{4}{|c|}{$n 16824$}} \\
\hline Q1 & \multicolumn{2}{|c|}{ Reference } & & ence & & & & \\
\hline Q2 & 16 & 9,23 & 16 & 9,23 & 0.00 & $-0.14,0.14$ & 0.04 & $-0.15,0.24$ \\
\hline Q3 & 18 & 11,25 & 19 & 12,26 & 0.07 & $-0.08,0.21$ & 0.22 & $0.01,0.42$ \\
\hline Q4 & 23 & 16,29 & 23 & 16,30 & 0.03 & $-0.12,0.17$ & 0.19 & $-0.03,0.41$ \\
\hline Q5 & 26 & 19,33 & 26 & 19,34 & -0.01 & $-0.15,0.14$ & 0.20 & $-0.04,0.44$ \\
\hline$P$ & & 001 & & 001 & & 0.911 & & 0.192 \\
\hline Overweight & & & & & & & & \\
\hline Q1 & & ence & & ence & & eference & & ference \\
\hline Q2 & 16 & 0,32 & 7 & $-9,23$ & 0.37 & $-0.03,0.77$ & 0.56 & $0.03,1.10$ \\
\hline Q3 & 30 & 14,46 & 20 & 3,36 & 0.32 & $-0.09,0.73$ & 0.47 & $-0.11,1.04$ \\
\hline Q4 & 41 & 25,57 & 31 & 14,47 & 0.39 & $-0.02,0.79$ & 0.76 & $0.15,1.36$ \\
\hline Q5 & 40 & 25,56 & 30 & 13,46 & 0.77 & $0.36,1 \cdot 17$ & 1.13 & $0.48,1.79$ \\
\hline$P$ & & 01 & & 001 & & 0.001 & & 0.016 \\
\hline Obese & & & & & & & & \\
\hline Q1 & & ence & & ence & & eference & & ference \\
\hline Q2 & 43 & 14,72 & 34 & 4,63 & 0.26 & $-0.72,1.24$ & -0.24 & $-1.45,0.97$ \\
\hline Q3 & 40 & 11,69 & 26 & $-4,56$ & 0.25 & $-0.73,1.24$ & 0.32 & $-0.96,1.60$ \\
\hline Q4 & 52 & 23,82 & 33 & 3,63 & 1.18 & $0 \cdot 18,2 \cdot 18$ & 1.55 & $0.19,2.90$ \\
\hline Q5 & 36 & 6,66 & 22 & $-8,53$ & $1 \cdot 12$ & $0 \cdot 11,2 \cdot 14$ & 1.29 & $0 \cdot 22,2 \cdot 80$ \\
\hline$P$ & & & & & & 0.006 & & 0.047 \\
\hline
\end{tabular}

${ }^{*}$ Adjusted for total energy intake, fibre intake, parity, mother's age, pre-pregnancy BMI, smoking habits, physical activity and couple's sociodemographic group.

†Adjusted for total energy intake, fibre intake, parity, mother's age, pre-pregnancy BMI, smoking habits, physical activity and couple's sociodemographic group, gestational weight gain and breast-feeding duration.

‡All women and stratified according to pre-pregnancy BMl (underweight, BMI $<18.5 \mathrm{~kg} / \mathrm{m}^{2}$; normal weight, BMI $18.5-24.9 \mathrm{~kg} / \mathrm{m}^{2}$; overweight, BMI $25 \cdot 0-29 \cdot 9 \mathrm{~kg} / \mathrm{m}^{2}$; obese, BMl $\left.\geq 30 \mathrm{~kg} / \mathrm{m}^{2}\right)$. 


\section{Postpartum weight retention}

Overall higher PPWR were detected in the three highest quintiles of GL compared with the lowest quintiles of GL, the differences being $0.29,0.44$ and $0.46 \mathrm{~kg}$, respectively (Table 3). When stratifying according to BMI, no association between the GL and PPWR was found among the underweight and normal-weight women. Among the overweight and obese women, substantially higher weight retention was found in the highest quintile; the mean weight gain was $1 \cdot 13$ (95\% CI 0.48 , 1.79 ) $\mathrm{kg}$ among the overweight women and 1.29 (95\% CI 0.22 , $2 \cdot 80) \mathrm{kg}$ among the obese women compared with the lowest quintiles, when adjusted for confounders, gestational weight gain and duration of breast-feeding.

\section{Interaction between pre-pregnancy $B M I$ and the glycaemic load}

One of the hypotheses in the present study is that the associations between dietary GL and gestational and birth outcomes differ in groups of maternal pre-pregnancy BMI, and that the associations are more pronounced among pre-pregnancy overweight women. To confirm this, interaction terms between quintiles of GL and pre-pregnancy BMI (underweight, normal weight, overweight and obese) were included in the univariate models, testing whether there were statistically significant interactions between the pre-pregnancy weight class and dietary GL. A statistically significant interaction between pre-pregnancy BMI and the GL in the analysis of the outcomes indicates that the influence of the GL on the outcome, e.g. gestational weight gain, is dependent upon the pre-pregnancy BMI class. Statistically significant interactions between pre-pregnancy BMI and dietary GL were detected in the analyses of birth weight, weight gain rate and PPWR, indicating stronger associations between the GL and birth weight, weight gain and PPWR with increasing pre-pregnancy BMI (results not shown). This underlines the hypothesis that the associations between the GL and outcomes differ between the groups of women defined by pre-pregnancy BMI. However, no statistically significant interactions were found in the analyses of SGA and LGA.

\section{Discussion}

In this large prospective cohort of pregnant women in Denmark, we found the associations between dietary GL in pregnancy and gestational weight gain, birth weight and PPWR.

Although being statistically significant, the increase in mean birth weight $(36 \mathrm{~g})$ from the lowest to the highest quintile of GL may not be of high clinical relevance. On the other hand, the increase in birth weight corresponds to a $14 \%$ increased risk of LGA babies in the high-GL group. No clear association between the GL and the risk of SGA was detected. The associations between the GI and birth weight have been examined previously in intervention studies ${ }^{(31,32)}$, and in one observational study ${ }^{(34)}$, all suggesting a positive association between the GI and birth weight. The findings rely on the fact that glucose is a major substrate for fetal growth ${ }^{(35)}$, and that altering the source of maternal dietary carbohydrate may be valuable in managing fetal overgrowth ${ }^{(45)}$.

We further observed that gestational weight gain, assessed between weeks 12 and 30 in gestation, was positively associated with GL. The association between the GL and gestational weight gain was also found in the study by Clapp ${ }^{(45)}$, but not in the studies by Moses et ll $^{(32)}$ or Scholl et al. ${ }^{(13)}$. The maximum increase in weight gain with increasing GL in the present study was detected among the overweight women, who on average gained $30 \mathrm{~g} /$ week more in the highest quintile of GL compared with the lowest quintile of GL. This weight gain rate corresponds to an average increase of approximately $1.2 \mathrm{~kg}$ for the whole pregnancy, which may be of importance in overweight women, who are recommended to restrict their weight during pregnancy ${ }^{(46)}$. Gestational weight gain has been reported to be positively associated with $\mathrm{PPWR}^{(47)}$, and implementation of a low-GI diet may thus be a useful guideline in the prevention of obesity among women of childbearing age. A low-GI diet, with an increased intake of vegetables and legumes, and whole-grain products are in line with existing food-based dietary guidelines, where an increased intake of these foods is recommended.

Even after adjustment for gestational weight gain and breast-feeding, the 18 months PPWR was also positively associated with GL in pregnancy, especially among the overweight and obese women. PPWR may contribute to the development of overweight and obesity, and the prevention of PPWR may therefore be of great public health impact. As the association between the GL and PPWR was strongest among women who were already overweight before pregnancy, and thus is a group to whom concern about weight development during pregnancy should be paid, the GL may be a useful tool in weight management. Further, a diet with a high GL has been associated with an increased risk of gestational diabetes ${ }^{(48)}$, which also points towards the benefits of following a low-GI diet during pregnancy for overweight women.

The strengths of the present study were the large sample size, as we included information on dietary intake covariates and outcome variables for 47003 women, and a large variety of covariates which allowed for adjusting for potential confounding factors. Information on dietary intake in pregnancy was recorded before birth weight and PPWR, which limits the risk of recall bias. However, under-reporting is an important issue in self-reported dietary intake data, and may be more pronounced among overweight individuals ${ }^{(49)}$. Therefore, women with the highest weight gain during pregnancy may be most likely to under-report their carbohydrate intake, leading to erroneous values of the GL of the diet. However, if this was the case in this cohort, the associations between the GL and weight gain, on the one hand, and PPWR, on the other hand, would have been attenuated and hence the true association may be even stronger than what was observed.

The GL in this cohort was assessed on the basis of internationally published values of the GI of foods ${ }^{(40)}$. The values of the GI vary by the brand name, the time of the year, the variety of the species tested and the method of cooking, and may as such vary in different countries, all factors 
adding uncertainty to the value of the GL included in the present study. A validation study of the FFQ used in the DNBC has shown that the FFQ gave valid estimates of total energy intake and the intake of protein, retinol and folic acid, and was capable of classifying the participants into the lowest and highest quintile ${ }^{(39)}$, which allows for comparisons of outcomes in the groups with high $v$. low dietary intake. We divided women into quintiles according to the dietary GL in the present study, allowing for comparisons of outcomes within the groups with a high $v$. low GL, respectively.

In summary, the present findings suggest that a diet with a high GL increases the risk of excessive weight gain during pregnancy and PPWR. The associations varied with the mother's pre-pregnancy weight, and were more pronounced among the overweight and obese women. Even though only a modest effect on birth weight was observed, attention should be paid to the fact that the quality of carbohydrate in the diet may affect the birth outcome.

\section{Acknowledgements}

We would like to thank the Danish Cancer Society for assisting with implementation of the values of the GI. Financial support was obtained from the March of Dimes Birth Defects Foundation, EARNEST (Food-CT-2005-007036) and DanORC. The managerial team of the DNBC consisted of Jørn Olsen (chair), Mads Melbye, Anne Marie Nyboe Andersen, S. F. O., T. I. A. S. and Peter Aaby. The authors' contributions were as follows: S. F. O. and V. K. K. contributed to the study concept and design; S. F. O., V. K. K. and T. I. H. had a role in the acquisition of the data; V. K. K., T. I. H., B. L. H., T. I. A. S. and S. F. O. were involved in the interpretation of the data and the critical review of the manuscript; V. K. K. performed the statistical analyses and wrote the draft of the manuscript. None of the authors had any conflict of interest.

\section{References}

1. Thorsdottir I, Torfadottir JE, Birgisdottir BE, et al. (2002) Weight gain in women of normal weight before pregnancy: complications in pregnancy or delivery and birth outcome. Obstet Gynecol 99, 799-806.

2. Stotland NE, Hopkins LM \& Caughey AB (2004) Gestational weight gain, macrosomia, and risk of cesarean birth in nondiabetic nulliparas. Obstet Gynecol 104, 671-677.

3. Jain NJ, Denk CE, Kruse LK, et al. (2007) Maternal obesity: can pregnancy weight gain modify risk of selected adverse pregnancy outcomes? Am J Perinatol 24, 291-298.

4. Brennand EA, Dannenbaum D \& Willows ND (2005) Pregnancy outcomes of First Nations women in relation to pregravid weight and pregnancy weight gain. J Obstet Gynaecol Can 27, 936-944.

5. Cedergren M (2006) Effects of gestational weight gain and body mass index on obstetric outcome in Sweden. Int J Gynaecol Obstet 93, 269-274.

6. Hackmon R, James R, O'Reilly Green C, et al. (2007) The impact of maternal age, body mass index and maternal weight gain on the glucose challenge test in pregnancy. J Matern Fetal Neonatal Med 20, 253-257.
7. Saldana TM, Siega-Riz AM, Adair LS, et al. (2006) The relationship between pregnancy weight gain and glucose tolerance status among black and white women in central North Carolina. Am J Obstet Gynecol 195, 1629-1635.

8. Kac G, Benicio MH, Velasquez-Melendez G, et al. (2004) Gestational weight gain and prepregnancy weight influence postpartum weight retention in a cohort of Brazilian women. J Nutr 134, 661-666.

9. Vesco KK, Dietz PM, Rizzo J, et al. (2009) Excessive gestational weight gain and postpartum weight retention among obese women. Obstet Gynecol 114, 1069-1075.

10. Gunderson EP \& Abrams B (2000) Epidemiology of gestational weight gain and body weight changes after pregnancy. Epidemiol Rev 22, 261-274.

11. Gunderson EP, Abrams B \& Selvin S (2000) The relative importance of gestational gain and maternal characteristics associated with the risk of becoming overweight after pregnancy. Int J Obes Relat Metab Disord 24, 1660-1668.

12. Melzer K \& Schutz Y (2010) Pre-pregnancy and pregnancy predictors of obesity. Int J Obes (Lond) 34, Suppl. 2, S44-S52.

13. Scholl TO, Hediger ML, Schall JI, et al. (1995) Gestational weight gain, pregnancy outcome, and postpartum weight retention. Obstet Gynecol 86, 423-427.

14. Hedderson MM, Weiss NS, Sacks DA, et al. (2006) Pregnancy weight gain and risk of neonatal complications: macrosomia, hypoglycemia, and hyperbilirubinemia. Obstet Gynecol $\mathbf{1 0 8}$ 1153-1161.

15. Jenkins DJ, Wolever TM, Taylor RH, et al. (1981) Glycemic index of foods: a physiological basis for carbohydrate exchange. Am J Clin Nutr 34, 362-366.

16. Lock DR, Bar-Eyal A, Voet H, et al. (1988) Glycemic indices of various foods given to pregnant diabetic subjects. Obstet Gynecol 71, 180-183.

17. Brand-Miller JC, Holt SH, Pawlak DB, et al. (2002) Glycemic index and obesity. Am J Clin Nutr 76, 281S-285S.

18. Flood A, Subar AF, Hull SG, et al. (2006) Methodology for adding glycemic load values to the National Cancer Institute Diet History Questionnaire database. J Am Diet Assoc 106, 393-402.

19. Salmeron J, Ascherio A, Rimm EB, et al. (1997) Dietary fiber, glycemic load, and risk of NIDDM in men. Diabetes Care 20, 545-550.

20. Salmeron J, Manson JE, Stampfer MJ, et al. (1997) Dietary fiber, glycemic load, and risk of non-insulin-dependent diabetes mellitus in women. JAMA 277, 472-477.

21. Schulz M, Liese AD, Mayer-Davis EJ, et al. (2005) Nutritional correlates of dietary glycaemic index: new aspects from a population perspective. Br J Nutr 94, 397-406.

22. Ludwig DS (2000) Dietary glycemic index and obesity. J Nutr 130, 280S-283S.

23. Lau C, Toft U, Tetens I, et al. (2006) Association between dietary glycemic index, glycemic load, and body mass index in the Inter99 study: is underreporting a problem? Am J Clin Nutr 84, 641-645.

24. Nielsen BM, Bjornsbo KS, Tetens I, et al. (2005) Dietary glycaemic index and glycaemic load in Danish children in relation to body fatness. Br J Nutr 94, 992-997.

25. Ma Y, Olendzki B, Chiriboga D, et al. (2005) Association between dietary carbohydrates and body weight. Am J Epidemiol 161, 359-367.

26. Romaguera D, Angquist L \& Du H (2010) Dietary determinants of changes in waist circumference adjusted for body mass index - a proxy measure of visceral adiposity. PLoS One 5, e11588.

27. Du H, van der ADL, van Bakel MM, et al. (2009) Dietary glycaemic index, glycaemic load and subsequent changes 
of weight and waist circumference in European men and women. Int J Obes (Lond) 33, 1280-1288.

28. Gaesser GA (2007) Carbohydrate quantity and quality in relation to body mass index. J Am Diet Assoc 107, $1768-1780$.

29. Thomas DE, Elliott EJ \& Baur L (2007) Low glycaemic index or low glycaemic load diets for overweight and obesity. The Cochrane Database of Systematic Reviews, issue 3, CD005105.

30. Larsen TM, Dalskov SM, van Baak M, et al. (2010) Diets with high or low protein content and glycemic index for weightloss maintenance. $N$ Engl J Med 363, 2102-2113.

31. Clapp JF (1997) Diet, exercise, and feto-placental Growth. Arch Gynecol Obstet 260, 101-108.

32. Moses RG, Luebcke M, Davis WS, et al. (2006) Effect of a low-glycemic-index diet during pregnancy on obstetric outcomes. Am J Clin Nutr 84, 807-812.

33. Rhodes ET, Pawlak DB, Takoudes TC, et al. (2010) Effects of a low-glycemic load diet in overweight and obese pregnant women: a pilot randomized controlled trial. Am J Clin Nutr 92, 1306-1315.

34. Scholl TO, Chen X, Khoo CS, et al. (2004) The dietary glycemic index during pregnancy: influence on infant birth weight, fetal growth, and biomarkers of carbohydrate metabolism. Am J Epidemiol 159, 467-474.

35. Herrera E (2000) Metabolic adaptations in pregnancy and their implications for the availability of substrates to the fetus. Eur J Clin Nutr 54, Suppl. 1, S47-S51.

36. Deierlein AL, Siega-Riz AM \& Herring A (2008) Dietary energy density but not glycemic load is associated with gestational weight gain. Am J Clin Nutr 88, 693-699.

37. Olsen J, Melbye M, Olsen SF, et al. (2001) The Danish National Birth Cohort - its background, structure and aim. Scand J Public Health 29, 300-307.

38. Olsen SF, Mikkelsen TB, Knudsen VK, et al. (2007) Data collected on maternal dietary exposures in the Danish National Birth Cohort. Paediatr Perinat Epidemiol 21, 76-86.

39. Mikkelsen TB, Osler M \& Olsen SF (2006) Validity of protein, retinol, folic acid and $n-3$ fatty acid intakes estimated from the food-frequency questionnaire used in the Danish National Birth Cohort. Public Health Nutr 9, 771-778.

40. Foster-Powell K, Holt SH \& Brand-Miller JC (2002) International table of glycemic index and glycemic load values: 2002. Am J Clin Nutr 76, 5-56.

41. Wolever TM, Nguyen PM, Chiasson JL, et al. (1994) Determinants of diet glycemic index calculated retrospectively from diet records of 342 individuals with noninsulin-dependent diabetes mellitus. Am J Clin Nutr 59, $1265-1269$.

42. Willett WC, Howe GR \& Kushi LH (1997) Adjustment for total energy intake in epidemiologic studies. Am J Clin Nutr 65 , 1220S-1228S (discussion 1229S-1231S).

43. Cole TJ, Freeman JV \& Preece MA (1998) British 1990 growth reference centiles for weight, height, body mass index and head circumference fitted by maximum penalized likelihood. Stat Med 17, 407-429.

44. Baker JL, Gamborg M, Heitmann BL, et al. (2008) Breastfeeding reduces postpartum weight retention. Am J Clin Nutr $\mathbf{8 8}$, $1543-1551$.

45. Clapp JF III (2002) Maternal carbohydrate intake and pregnancy outcome. Proc Nutr Soc 61, 45-50.

46. Sundhedsstyrelsen (Danish National Board of Health) (2010) Healthy habits before, during and after pregnancy. Copenhagen: Danish National Board of Health. www.sst.dk/publ/ publ2010/CFF/English/SundeVaner_en.pdf.

47. Nohr EA, Vaeth M, Baker JL, et al. (2009) Pregnancy outcomes related to gestational weight gain in women defined by their body mass index, parity, height, and smoking status. Am J Clin Nutr 90, 1288-1294.

48. Zhang C, Liu S, Solomon CG, et al. (2006) Dietary fiber intake, dietary glycemic load, and the risk for gestational diabetes mellitus. Diabetes Care 29, 2223-2230.

49. Heitmann BL \& Lissner L (1995) Dietary underreporting by obese individuals - is it specific or non-specific? BMJ $\mathbf{3 1 1}$, 986-989. 